\title{
Association between Chronic Obstructive Pulmonary Disease and Coronary Artery Disease
}

\author{
${ }^{1}$ Sonkamble Siddharth, ${ }^{2}$ Sangeeta Pednekar,${ }^{3}$ R. H. Girde, ${ }^{4}$ Shilpa Patil, \\ ${ }^{5}$ S. T. Nabar \\ ${ }^{1,4}$ Assistant Professor, ${ }^{2,5}$ Professor, ${ }^{3}$ Resident \\ ${ }^{1,2}$ Dept. of Medicine, L. T. M. Medical College and General Hospital, Sion, Mumbai, India \\ ${ }_{3,4,5}$ T.N. Medical College and BYL Nair Charitable Hospital, Mumbai, India
}

\begin{abstract}
:
Introduction: Both Chronic obstructive pulmonary disease (COPD) and coronary artery disease (CAD) are global epidemics, each affecting in excess of 10 million patients. Both conditions co-exist at different rates and incur significant morbidity and mortality, and present major challenges to healthcare providers. In the developing world the prevalence of CAD is increasing but the prevalence of COPD is unknown. This study was designed to estimate the proportion of patients with CAD who have concomitant COPD and identify factors that may increase the likelihood of $C O P D$ in $C A D$ patients.

Materials and Methods: A cross sectional study that included 100 consecutive patients of CHD attending the Medicine OPD of the LTMMC Sion and BYL Nair hospital fulfilling the inclusion and exclusion criteria were selected for study. All the patients underwent spirometry using an electronic spirometer. COPD was diagnosed using GOLD classification. Results were analysed using SPSS ver. 19.

Results: The mean age (SD) of study subjects was 48.3 (7.7) years. Of the 100 patients; 19 had COPD as per the GOLD classification. COPD was significantly more among patients with severe cardiac dysfunction, smokers and age above 60 years $(p<0.01)$.

Conclusion: In this group of patients with CAD about one in five has concomitant COPD. This will have enormous burden on health expenditure in a region where health budgets are already strained by costs of compacting endemic diseases. The prevalence rate we recorded warrants routine screening of all CAD patients for COPD specially those with severe cardiac dysfunction, h/o smoking and elderly.
\end{abstract}

Key words: Age, Cardiac abnormality, Chronic obstructive pulmonary disease, Coronary artery disease, Prevalence

\section{Introduction}

Cardiovascular Disease (CVD) is today the largest single contributor to global mortality and will continue to dominate mortality trends in the future. [1] Both CVD and Chronic Obstructive Pulmonary Disease (COPD) are global epidemics, each affecting in excess of 10 million patients. [1,2] Both conditions incur significant morbidity and mortality, and present major challenges to healthcare providers. [2]

Coronary Artery disease (CAD) is the most common type of heart disease and cause of heart attacks. The disease is caused by plaque building up along the inner walls of the arteries of the heart, which narrows the arteries and reduces blood flow to the heart. CAD is likely to become the most common cause of death worldwide by 2020 . [3]

Chronic obstructive pulmonary disease (COPD), a common preventable and treatable disease, is characterized by persistent, usually progressive airflow limitation and is associated with an enhanced chronic inflammatory response of the airways and the lung to noxious particles or gases.[2]

It is now well established that Chronic Obstructive Pulmonary Disease (COPD) is a chronic inflammatory condition with significant extrapulmonary manifestations. [4] In patients with mild-to moderate COPD, the leading cause of morbidity and mortality is cardiovascular disease. In the Lung Health Study, which examined nearly 6,000 smokers whose FEV1 was between $55 \%$ and $90 \%$ predicted, cardiovascular diseases were the leading cause of hospitalization, accounting for nearly $50 \%$ of all hospital admissions, and the second leading cause of mortality, accounting for a quarter of all deaths. [5]

Subsequent studies have confirmed that, on average, patients with COPD have two to three times the risk of hospitalization for cardiovascular conditions (including ischemic heart disease, stroke, and heart failure) compared to those patients without COPD. [6]

Although COPD and CAD have common causal factors, primarily smoking, the increase of CAD in patients with COPD is independent of these known risk factors.[7] The exact mechanism linking COPD to heart disease is not yet known, but systemic inflammation, oxidative stress and hypoxemia are the major putative candidates. Of these, systemic inflammation is supported by the greatest amount of evidence. 
Low grade systemic inflammation occurs in patients with clinically stable COPD and in many other chronic conditions, including CAD. Furthermore, in COPD, systemic inflammation persists after smoking cessation [8] and increases during the exacerbation of the disease. Notably, it is during exacerbations that patients with COPD have the highest risk of a cardiovascular event. [9]

The aim of present study was to find the prevalencee of COPD in CAD patients and study various associated factors.

\section{Materials \& Methods}

A cross sectional study was conducted between January 2010 to December 2012 at tertiary care hospitals and medical colleges of Mumbai, after obtaining permission from Institutional Ethical Committee (IEC). A total of 100 consecutive patients of CHD attending the Medicine OPD of the parent hospital fulfilling the inclusion and exclusion criteria were selected for study after obtaining informed consent.

Inclusion criteria (for case of CHD):

1. Past ECG changes; or

2. Stress test proved; or

3. 2-D Echo/ Angiography proved

Exclusion Criteria:

1. Cardiac Failure

2. Prior Pulmonary TB

3. Known case of Bronchial Asthma

4. Interstitial lung disease

5. Renal Failure

Spirometry was performed on all patients using an electronic spirometer: (Spida 5, Micromedical, England). The manoeuvre was explained to each subject and the best of three readings was recorded. Height was measured to the nearest centimetre and weight was recorded to the nearest kilogram. A study diagnosis of COPD was assigned using GOLD criteria: [10]

\begin{tabular}{|l|l|l|}
\hline \multicolumn{3}{|l|}{ Spirometric classification of chronic obstructive pulmonary disease (COPD) } \\
\hline Severity & Post bronchodilator $\mathrm{FEV}_{1} / \mathrm{FVC}$ & $\mathrm{FEV}_{1} \%$ predicted \\
\hline At risk & $>0.7$ & $\geq 80$ \\
\hline Mild COPD & $<0.7$ & $\geq 80$ \\
\hline Moderate COPD & $<0.7$ & $50-79$ \\
\hline Severe COPD & $<0.7$ & $30-49$ \\
\hline Very severe COPD & $<0.7$ & $<30$ \\
\hline
\end{tabular}

\# patients who smoke or have exposure to pollutants, have cough, sputum or dyspnoea

The New York Heart Association (NYHA) Functional Classification was used for assessment of cardiac dysfunction. [11]

\begin{tabular}{|l|l|}
\hline $\begin{array}{l}\text { NYHA } \\
\text { Class }\end{array}$ & Symptoms \\
\hline I & $\begin{array}{l}\text { Cardiac disease, but no symptoms and no limitation in ordinary physical activity, e.g. shortness of breath } \\
\text { when walking, climbing stairs etc. }\end{array}$ \\
\hline II & Mild symptoms (mild shortness of breath and/or angina) and slight limitation during ordinary activity. \\
\hline III & $\begin{array}{l}\text { Marked limitation in activity due to symptoms, even during less-than-ordinary activity, e.g. walking short } \\
\text { distances } \\
\text { Comfortable only at rest. }\end{array}$ \\
\hline IV & Severe limitations. Experiences symptoms even while at rest. Mostly bedbound patients. \\
\hline
\end{tabular}

All the data was collected using a pre-formed, pre-tested, semi structured questionnaire and entered in MS Excel spreadsheet ver. 2007. The data was then transferred and analysed using SPSS ver. 19 software using appropriate statistical tests. P- value of $<0.05$ was considered as significant.

\section{Results}

The mean age of study subjects was $48.3 \pm 7.7$ years. Out of the total 100 study subjects 44 were females and 56 were males. The overall prevalence of COPD as diagnosed using GOLD criteria was 19\% (table 1). Distribution of patients as per NYHA classification (table 2) showed 62\% patients had cardiac disease, but no 
symptoms and no limitation in ordinary physical activity (NYHA class I). On evaluating the association of various demographic and clinical characteristics of patients with COPD (table 3), we found increasing age (> 60 years), severe cardiac abnormality (NYHA Class II/ III), diastolic dysfunction and history of smoking were significantly associated with increased risk of COPD.

\section{Discussion}

The present study has shown that around one in five patients (19\%) with CAD have concomitant COPD. Prior work has demonstrated that CAD and COPD co-morbidity exists at different rates. [12-15] However, these studies were either retrospective or were conducted in primary care settings where the diagnoses of CAD was made on clinical grounds. $[14,15]$ The difference in prevalence between previous work and our study may be explained by the fact that the present study was hospital based and only diagnosed cases of CHD were taken for the study. Moreover, the present study was conducted in a developing world country where the epidemiology of CAD and COPD are likely to be different compared with those of the developed world. Nevertheless, the prevalence rate recorded in this study is high enough to warrant COPD screening of all patients with proven CAD.

Epidemiological studies have shown that the developing world will bear the brunt of the worldwide increasing incidence of CAD and CAD mortality. [16] Given these projected increases in CAD the high prevalence of COPD co-morbidity in CAD patients shown in this study will have an enormous burden in terms of disability, mortality and health expenditure in developing world countries. $[12,17,18]$ This will be an add on to health budgets that are already exhausted by the load of treating and preventing endemic diseases.

Diastolic dysfunction on 2 D- Echo was found to be associated with COPD. Similar association was found in various other studies. [19-21]

Our study identified three main risk factors for COPD and CAD co-morbidity: increasing age, smoking and advanced cardiac dysfunction. Community based studies have shown that the prevalence of COPD increases with increasing age and it is significantly associated with history of smoking. [22-25] It was, therefore, not surprising to find significantly more COPD in older patients and smokers. In a study Ahmed AE et al. [27] found the prevalence of COPD and CAD as co-morbidity in smokers to be $39 \%$ which support the findings of the present study.

Severity of cardiac dysfunction was found to be associated with development of COPD. Similar observations were made by Patel AR et al. [27] who studied the the impact of ischemic heart disease on symptoms, health status, and exacerbations in patients with COPD. They conclude that patients with COPD and co-morbid IHD have more breathlessness, lower exercise capacity and poorer health status.

\section{Conclusion}

In conclusion this study has shown that $19 \%$ of patients with proven CAD have concomitant COPD in a developing country- India. This will have enormous burden on health expenditure in a region where health budgets are already strained by costs of compacting endemic diseases. Given the projected increases in the incidence of $\mathrm{CAD}$ in this part of the world the problem is likely to get worse. The prevalence rate we recorded warrants routine screening of all CAD patients for COPD specially those with severe cardiac dysfunction, history of smoking and elderly population. Further large scale studies are needed to determine future trends and define the epidemiology of COPD better.

\section{Acknowledgment}

Authors acknowledge the great help received from the scholars whose articles cited and included in references of this manuscript. The authors are also grateful to authors / editors / publishers of all those articles, journals and books from where the literature for this article has been reviewed and discussed.

\section{Bibliography}

[1]. Fuster, Valentin, and Bridget B. Kelly, eds. Promoting cardiovascular health in the developing world: a critical challenge to achieve global health. National Academies Press, 2010.

[2]. GOLD Global Initiative for Chronic Obstructive Lung Disease. Global strategy for the diagnosis, management, and prevention of chronic obstructive pulmonary disease: NHLBI/WHO workshop report. 2006; Updated $2006 \mathrm{http} / /$ www. goldcopd.com/.

[3]. Elliot M, Andrew P. Harrison`s Principles of Internal medicine. Ischemic Heart Disease. The McGraw-Hill Companies, Maryland, Baltimore, $17^{\text {th }}$ edition 2008; 338:2275-2304.

[4]. Rabe KF, Hurd S, Anzueto A, et al. Global strategy for the diagnosis, management, and prevention of chronic obstructive pulmonary disease: GOLD executive summary. Am J Respir Crit Care Med 2007; 176:532-555.

[5]. Anthonisen NR, Connett JE, Kiley JP, et al. Effects of smoking intervention and the use of an inhaled anticholinergic bronchodilator on the rate of decline of FEV1: the Lung Health Study. JAMA 1994; 272:1497-1505.

[6]. Sidney S, Sorel M, Quesenberry CP Jr, et al. COPD and incident cardiovascular disease hospitalizations and mortality: Kaiser Permanente Medical Care Program. Chest 2005; 128: 2068-2075.

[7]. Mannino DM, Thorn D, Swensen A et al. Prevalence and outcomes of diabetes, hypertension and cardiovascular disease in COPD. Eur. Respir. J. 2008; 32: 962-9.

[8]. Sin DD,Man SF. Systemic inflammation and mortality in chronic obstructive pulmonary disease. Can. J. Physiol. Pharmacol. 2007; 85: 141-7. 
[9]. Donaldson GC, Hurst JR, Smith CJ et al. Increased risk of myocardial infarction and stroke following exacerbation of COPD. Chest 2010; 137: 1091-7.

[10]. Celli BR, MacNee W, and committee members. Standards for the diagnosis and treatment of patients with COPD: a summary of the ATS/ERS position paper. Eur Respir J 2004; 23:932-46.

[11]. The Criteria Committee of the New York Heart Association. (1994). Nomenclature and Criteria for Diagnosis of Diseases of the Heart and Great Vessels. (9th ed.). Boston: Little, Brown \& Co. pp. 253-256.

[12]. Sin D, Hand SFP. Chronic obstructive pulmonary disease as a risk factor for cardiovascular morbidity and mortality. Pro Am Thoracic Soc 2005;(2):8-11.

[13]. Wijnhoven HAH, Kriegsman DMW, Hesselink AE et al. The influence of co-morbidity on health-related quality of life in asthma and COPD patients. Respir Med 2003;97:468-75.

[14]. Holguin F, Folch E, Redd SC et al. Comorbidity and Mortality in COPD Related Hospitalizations in the United States, 1979 to 2001. Chest 2005;128:2005-11.

[15]. Soriano JB, Visick GT, Muellerova H, et al. Patterns of comorbidities in newly diagnosed COPD and asthma in primary Care. Chest 2005;128:2099-2107.

[16]. Okrainec K, Banerjee DK, Eisenberg MJ. Coronary artery disease in the developing world. Am Heart J. 2004;148(1):7-15.

[17]. Murray CJL, Lopez AD. Alternative projections of mortality and disability by cause 1990-2020: Global Burden of Disease Study. Lancet1997;349:1498-1504.

[18]. Sullivan SD, Ramsey SD, Lee TA. The Economic Burden of COPD. Chest 2000;117;5-9.

[19]. Funk, Georg-Christian, et al. Left ventricular diastolic dysfunction in patients with COPD in the presence and absence of elevated pulmonary arterial pressure. Chest. 2008;133(6): 1354-1359.

[20]. Abusaid, Ghassan H, et al. Diastolic dysfunction and COPD exacerbation. Postgrad Med. 2009;121(4):76-81.

[21]. Caram, Laura Miranda de Oliveira, et al. Association between left ventricular diastolic dysfunction and severity of chronic obstructive pulmonary disease. Clinics. 2010;68(6):772-776.

[22]. Lindberg A, Eriksson B, Larsson LG et al. Seven-year cumulative incidence of COPD in an age-stratified general population sample. Chest 2006;129:879-85.

[23]. Menezes MB, Perez-Padilla R, Jardim JB, et al. for the PLATINO Team. Chronic obstructive pulmonary disease in five Latin American cities (the PLATINO study): a prevalence study. Lancet 2005;366:1875-81.

[24]. Mannino, David M., and A. Sonia Buist. "Global burden of COPD: risk factors, prevalence, and future trends." The Lancet. 2007;370(9589):765-773.

[25]. Coultas, David B. "Passive smoking and risk of adult asthma and COPD: an update." Thorax. 1998;53(5):381-387.

[26]. Ahmed AE, Tarig EY, and Faris M. "Prevalence of chronic obstructive pulmonary disease in patients with catheter-diagnosed coronary artery disease." Annals of thoracic medicine. 2009;4(2):91.

[27]. Patel AR, Donaldson GC, Mackay AJ, Wedzicha JA, Hurst JR. The Impact of Ischemic Heart Disease on Symptoms, Health Status and Exacerbations in Patients with COPD. Chest. 2009;141(4): 851-857.

Table 1. Distribution of patients based on classification of COPD (GOLD criteria).

\begin{tabular}{lll}
\hline COPD Classification $(\mathbf{n}-\mathbf{1 0 0})$ & $\mathbf{N}$ & $\mathbf{\%}$ \\
\hline Normal & 81 & 81 \\
Moderate COPD & 17 & 17 \\
Severe COPD & 2 & 2 \\
Very Severe COPD & 0 & 0 \\
\hline
\end{tabular}

Table 2. Distribution of patients based on NYHA classification

\begin{tabular}{lll}
\hline NYHA Classification (n-100) & N & \% \\
\hline Asymptomatic & 11 & 11 \\
NYHA I & 62 & 62 \\
NYHA II & 25 & 25 \\
NYHA III & 2 & 2 \\
\hline
\end{tabular}

Table 3. Association of Demographic and clinical characteristics of patients with COPD.

\begin{tabular}{|c|c|c|c|c|c|}
\hline Variables (n-100) & & $\begin{array}{l}\text { COPD } \\
\text { Yes (n-19) }\end{array}$ & No (n-81) & Total & p-value \\
\hline \multirow{2}{*}{$\operatorname{Sex}(\%)$} & Female & $9(20.5)$ & $35(79.5)$ & 44 & \multirow{2}{*}{0.94} \\
\hline & Male & $10(17.9)$ & $46(82.1)$ & 56 & \\
\hline \multirow{2}{*}{ Age $(\%)$} & $<60$ years & $7(11.5)$ & $54(88.5)$ & 61 & \multirow{2}{*}{0.02} \\
\hline & $\geq 60$ years & $12(30.7)$ & $27(69.2)$ & 39 & \\
\hline \multirow{3}{*}{ Cardiac Dysfunction (\%) } & Normal/ NYHA I & $7(9.6)$ & $66(90.4)$ & 73 & \multirow{3}{*}{$<0.01$} \\
\hline & NYHA II/ III & $12(44.4)$ & $15(55.6)$ & 27 & \\
\hline & Normal & $1(2.7)$ & $36(97.3)$ & 37 & \\
\hline \multirow[t]{2}{*}{2 D- Echo $(\%)$} & Systolic dysfunction & $4(8.7)$ & $42(91.3)$ & 46 & \multirow[t]{2}{*}{$<0.01$} \\
\hline & Diastolic Dysfunction & $14(82.4)$ & $3(17.6)$ & 17 & \\
\hline \multirow[t]{2}{*}{ H/o Smoking (\%) } & Yes & $13(31.7)$ & $28(68.3)$ & 41 & \multirow{2}{*}{$<0.01$} \\
\hline & No & $6(10.2)$ & $53(89.8)$ & 59 & \\
\hline
\end{tabular}

